\title{
Thermal and physical stresses induce a short-term immune priming effect in Galleria mellonella larvae
}

\author{
Niall Browne, Carla Surlis, Kevin Kavanagh* \\ Department of Biology, NUI Maynooth, Co. Kildare, Ireland
}

\section{A R T I C L E I N F O}

\section{Article history:}

Received 8 October 2013

Received in revised form 11 February 2014

Accepted 12 February 2014

Available online 20 February 2014

\section{Keywords:}

Insect

Galleria

Larvae

Immune priming

Immune response

Immunity

\begin{abstract}
A B S T R A C T
Exposure of larvae of Galleria mellonella larvae to mild physical (i.e. shaking) or thermal stress for $24 \mathrm{~h}$ increased their ability to survive infection with Aspergillus fumigatus conidia however larvae stressed in a similar manner but incubated for $72 \mathrm{~h}$ prior to infection showed no elevation in their resistance to infection with A. fumigatus. Stressed larvae demonstrated an elevated haemocyte density $24 \mathrm{~h}$ after initiation of the stress event but this declined at 48 and $72 \mathrm{~h}$. Larval proteins such as apolipophorin, arylophorin and prophenoloxidase demonstrated elevated expression at $24 \mathrm{~h}$ but not at $72 \mathrm{~h}$. Larvae maintained at $37^{\circ} \mathrm{C}$ showed increased expression of a range of antimicrobial and immune-related proteins at $24 \mathrm{~h}$ but these decreased in expression thereafter. The results presented here indicate that $G$. mellonella larvae are capable of altering their immune response following exposure to mild thermal or physical stress to mount a response capable of counteracting microbial infection which reaches a peak $24 \mathrm{~h}$ after the initiation of the priming event and then declines by $72 \mathrm{~h}$. A short-term immune priming effect may serve to prevent infection but maintaining an immune priming effect for longer periods may be metabolically costly and unnecessary while living within the colony of another insect.
\end{abstract}

(c) 2014 Elsevier Ltd. All rights reserved.

\section{Introduction}

Although lacking an adaptive immune response comparable to that of vertebrates, insects display a highly effective immune response that consists of interconnected cellular and humoral components. The cellular immune response of insects is mediated by haemocytes which can engulf, encapsulate or neutralize pathogens (Ratcliffe, 1993; Pech and Strand, 1996). Free floating haemocytes in the haemocoel are first to the site of infection and their numbers can be supplemented by the release of haemocytes bound to internal organs such as the fat body (Kavanagh and Reeves, 2004). The humoral immune response of insects is mediated by a variety of mechanisms including anti-microbial peptide production, (Ratcliffe, 1985) melanisation, haemolymph clotting (Kavanagh and Reeves, 2004) that impede the growth and development of the pathogen within the host.

Insects may encounter a number of stresses within their environment including infection, injury or abiotic factors such as temperature fluctuations and changes in nutrient availability. The gene responses in Drosophila melanogaster have been demonstrated to

\footnotetext{
Abbreviations: PO, phenoloxidase; PPO, prophenoloxidase.

* Corresponding author. Tel.: +353 1708 3859; fax: +3531 1083845 .

E-mail address: kevin.kavanagh@nuim.ie (K. Kavanagh).
}

be altered in response to invasion of a specific pathogen (De Gregorio et al., 2001; Irving et al., 2001). It has also been shown that insects may be primed against infection by certain pathogens based on prior exposure (Bergin et al., 2006; Little and Kraaijeveld, 2004). The availability of nutrients can also affect the insect immune response. Previous work demonstrated that dietary restriction can lead to an altered expression of a number of immune related genes and a delayed up-regulation of antimicrobial genes in D. melanogaster (Pletcher et al., 2005).

Immune priming has obvious survival advantages for the host and has been observed in a wide range of invertebrates including D. melanogaster (De Gregorio et al., 2001), Anopheles (Heard et al., 2005), Caenorhabditis elegans (Schulenburg et al., 2004) and Molluscs (Zhang and Loker, 2004). Inoculation of D. melanogaster with a sub-lethal dose of Streptococcus pneumoniae protected against a subsequent lethal inoculum and was mediated by a change in the density of circulating phagocytic cells (Pham et al., 2007). In Bombus terrestris the protection and specificity of immune priming can last up to 22 days, which is long after transcription and the elevated production of antimicrobial peptides has ended (Sadd and Schmid-Hempel, 2006).

Immune priming has been demonstrated in Galleria mellonella larvae following infection with sub-lethal doses of yeast (Bergin et al., 2006), fungal cell wall components (Mowlds et al., 2010), 


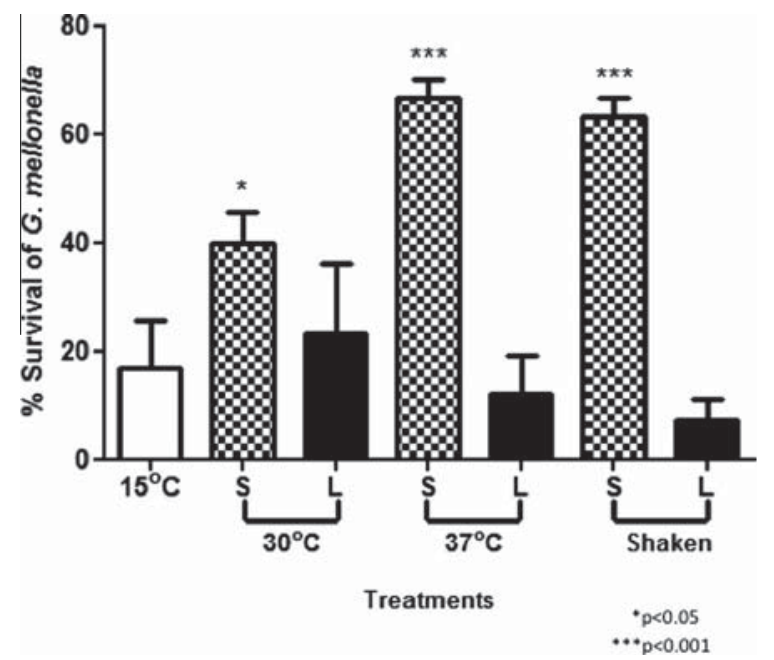

Fig. 1. Survival of G. mellonella larvae following incubation for 24 or $72 \mathrm{~h}$ prior to infection with A. fumigatus conidia. Larval survival was assessed $72 \mathrm{~h}$ post-infection. Control larvae were kept at $15{ }^{\circ} \mathrm{C}$ prior to inoculation. All larvae were incubated at $30{ }^{\circ} \mathrm{C}$ post-infection.

antifungal drugs (Rowan et al., 2009) and mild physical or thermal stress (Mowlds et al., 2008; Mowlds and Kavanagh 2008). Previous work demonstrated the differential expression of four genes in response to physical stress where galiomicin and IMPI demonstrated an increase in expression while transferrin and gallerimycin remained relatively unchanged (Mowlds et al., 2008). Thermally stressed larvae demonstrated elevated expression of a number of antimicrobial genes that enable increased resistance to infection (Mowlds et al., 2008, Wojda and Jakubowicz, 2007). Analysis of the effects of thermal and physical stress on G. mellonella larvae highlights the potential differential and proportional responses elicited by these stresses which appear to be similar to that observed in insects in response to microbial infections (Lemaitre et al., 1997; Bergin et al., 2006).

The immune system of insects shows strong structural and functional similarities to the innate immune system of mammals and results obtained using microbial pathogens in insects show a strong correlation to those generated using mammals (Jander et al., 2000; Mukherjee et al., 2013). G. mellonella larvae are widely used as model organisms for assessing the virulence of microbial pathogens or for determining the efficacy of antimicrobial agents (Kavanagh and Fallon, 2010). The aim of the work presented here was to establish whether an immune priming effect in G. mellonella larvae, induced as a result of exposure to mild physical or thermal stresses, was of short or long duration. Knowledge of how G. mellonella larvae respond to stress is important from a developmental point of view but would also inform how these insects could be used as in vivo models.

\section{Materials and methods}

\subsection{Chemicals and reagents}

All chemicals and reagents were of the highest purity and were purchased from Sigma-Aldrich Chemical Company Ltd (Dorset, UK) unless stated otherwise.

\subsection{Fungal strain and culture conditions}

Aspergillus fumigatus ATCC 26933 (obtained from the American Type Culture Collection) was grown on malt extract agar (MEA,
Oxoid) plates at $37^{\circ} \mathrm{C}$ and conidia were harvested by washing with PBS Tween $(0.01 \% \mathrm{v} / \mathrm{v})$ solution.

\subsection{Insect larvae}

Sixth instar larvae of G. mellonella (Lepidoptera: Pyralidae, the Greater Wax Moth) (Mealworm Company, Sheffield, England) were stored in the dark at $15{ }^{\circ} \mathrm{C}$ to stop their development (Cotter et al., 2000, Hornsey and Wareham, 2011). Larvae of the same age and of equivalent weights $(0.277 \pm 0.005 \mathrm{~g})$ were inoculated with $1 \times 10^{7}$ A. fumigatus conidia per $20 \mu \mathrm{l}$ PBS through the last pro-leg into the haemolymph using a Myjector U100 insulin syringe (Terumo Europe, Leuven, Belgium).

\subsection{Larval thermal and physical stress treatments}

Prior to infection with A. fumigatus conidia larvae were maintained at $30^{\circ} \mathrm{C}$ or $37^{\circ} \mathrm{C}$, or physically stressed by gentle shaking for $2 \mathrm{~min}$ and incubated at $30^{\circ} \mathrm{C}$, for $24 \mathrm{~h}$ (this is described as short term incubation $(\mathrm{S})$ ). Larvae were also stressed in a similar way to the short term incubated larvae but incubated at $30^{\circ} \mathrm{C}$ for an extra $48 \mathrm{~h}$ prior to infection (this is described as long term incubation (L)). Control larvae were incubated at $15^{\circ} \mathrm{C}$ for $24 \mathrm{~h}$ prior to inoculation. All larvae were placed at $30^{\circ} \mathrm{C}$ once inoculated, and larval survival was assessed $72 \mathrm{~h}$ post infection.

Larvae were physically stressed by being gently shaken in cupped hands through a distance of $25 \mathrm{~cm}$ in a vertical motion at a frequency of 80 times per minute for a period of 2 min (Mowlds et al., 2008). This treatment had no effect on the survival of larvae. Ten larvae were used per treatment and all experiments were performed on three independent occasions.

\subsection{Determination of haemocyte density}

Haemocyte density was assessed by bleeding three larvae into a pre-chilled tube containing $0.37 \%(\mathrm{v} / \mathrm{v})$ mercaptoethanol in sterile IPS $(150 \mathrm{mM} \mathrm{NaCl}, 5 \mathrm{mM} \mathrm{KCl}, 0.1 \mathrm{M}$ Tris- $\mathrm{HCl}, 10 \mathrm{mM}$ EDTA and $30 \mathrm{mM}$ Trisodium citrate in $\mathrm{dH}_{2} \mathrm{O}, \mathrm{pH}$ 6.9) to prevent melanisation and the haemocyte density was assessed using a Neubauer haemocytometer. Experiments were performed on three independent occasions and the means \pm SE were determined.

\subsection{D SDS-PAGE analysis of protein expression}

Larvae were stressed as described and incubated at 15,30 or $37{ }^{\circ} \mathrm{C}$ for 24,48 or $72 \mathrm{~h}$. Ten larvae per treatment were bled through the anterior region into pre-chilled micro-centrifuge tubes and the haemocytes were removed by centrifugation at $800 \mathrm{~g}$ for $5 \mathrm{~min}$ at $4{ }^{\circ} \mathrm{C}$. Cell free haemolymph $(100 \mu \mathrm{l})$ was diluted in ice-cold IPS and protein quantified by Bradford assay. Protein concentration was adjusted to $20 \mathrm{mg}(\mu \mathrm{g})$ in $5 \times$ solubilisation buffer (glycerol; 52\%, 10\% (v/v) SDS; 10.5\%, $1.5 \mathrm{M}$ Tris-HCl; $6.5 \%$, bromophenol blue $(0.5 \% \mathrm{w} / \mathrm{v}) ; 1.3 \% 2$-mercaptoethanol; $2.63 \%)$ and incubated at $95{ }^{\circ} \mathrm{C}$ for $5 \mathrm{~min}$. Samples were separated by 1-dimensional SDS-PAGE and visualized by Coomassie staining. Relative quantification of protein bands was carried out using Image J 1.46 software on each matching band.

\subsection{D SDS-PAGE separation of haemolymph proteins and image analysis}

Haemolymph $(100 \mu \mathrm{l})$ was collected from larvae that had been incubated at $37^{\circ} \mathrm{C}$ for 24,48 or $72 \mathrm{~h}$ by piercing the head of the insect and bleeding the haemolymph into a pre-chilled microcentrifuge tube. Protein concentration was determined by the Bradford method and $400 \mu \mathrm{g}$ of protein was acetone precipitated 
per sample. Isoelectric focusing of protein samples on a $\mathrm{pH}$ 4-7 strip and 2D electrophoresis was performed as described previously (Bergin et al., 2006). Each 2D gel was scanned on a Hewlett Packard scanjet 5100c scanner and the images were analyzed using Progenesis SameSpot Software. The Progenesis software enabled the analysis of protein expression changes between gel replicates with significance determined using ANOVA. The program enables alignment of gels, with minor distortions between gels reduced by running all replicates at one time. The alignment software enables the user to link proteins manually between gels which in conjunction with the Auto alignment feature automatically match proteins between gels. A table of protein spots is built and every given protein has been linked to the matching proteins between the gels creating a list of proteins that can be cross referenced as a final check to ensure correct alignment.

\subsection{LC/MS analysis of peptides}

In-gel digestion was performed on 1-Dimensional gel bands or 2-Dimensional gel spots of interest from a reference gel with proteins migrated to the same point between gels. The gel pieces were trypsin digested as described by Shevchenko et al. (2006) and fragmented protein samples were eluted by LC/MS (Aglient 6340 Ion Trap) which determines the relative charge to mass ratio from detected ionized particles. These data were analysed using the mascot search engine to identify the protein, (www.matrixscience.com). MASCOT scores above 67 were deemed to have a significant match $(p<0.05)$. The mass error tolerance was 1 Da allowing for a maximum of no more than two missed cleavages. Verification of protein sequences was confirmed by blasting the protein sequence on the Uniprot (www.uniprot.org) and NCBI (www.ncbi.nlm.nih.gov) websites.

\subsection{Statistical analysis}

All experiments were performed on three independent occasions and results are expressed as the mean \pm SE. Changes in larval survival were analysed with the log rank (Mantel-Cox) method using GraphPad Prism version 5.00. Analysis of changes in haemocyte density and protein expression were performed by Two-way ANOVA using GraphPad Prism version 5.00 for Windows 8, GraphPad Software, San Diego, California, USA, (www.graphpad.com).

\section{Results}

\subsection{Effect of physical and thermal stress on ability of G. mellonella larvae to survive fungal infection}

Larvae of G. mellonella were physically or thermally stressed as described and incubated for a short $(24 \mathrm{~h})$ or long $(72 \mathrm{~h})$ period prior to infection with $A$. fumigatus. Larval survivals were assessed $72 \mathrm{~h}$ post infection. Larvae incubated at $30^{\circ} \mathrm{C}$ for $24 \mathrm{~h}$ prior to infection showed $40.0 \pm 5.8 \%$ survival $72 \mathrm{~h}$ post-infection ( $p=0.05$ vs control larvae) while those larvae incubated at $30^{\circ} \mathrm{C}$ for $72 \mathrm{~h}$ prior to infection (L) showed $23.1 \pm 12.8 \%$ survival at the same time point. Larvae pre-incubated at $37^{\circ} \mathrm{C}$ for $24 \mathrm{~h}$ prior to infection showed $66.7 \pm 3.3 \%(p=0.001)$ survival while those larvae that were incubated at $37^{\circ} \mathrm{C}$ for $24 \mathrm{~h}$ and then at $30^{\circ} \mathrm{C}$ for $48 \mathrm{~h}$ prior to infection showed $12.0 \pm 7.23 \%$ survival. Larvae physically stressed and incubated at $30^{\circ} \mathrm{C}$ for $24 \mathrm{~h}$ demonstrated $63.3 \pm 3.3 \%$ survival $(p=0.001)$ while those larvae stressed and incubated at $30^{\circ} \mathrm{C}$ for $72 \mathrm{~h}$ showed $7.3 \pm 3.7 \%$ survival. These results indicate that larvae incubated at 30 or $37^{\circ} \mathrm{C}$, or physically stressed, for $24 \mathrm{~h}$ prior to infection showed increased survival

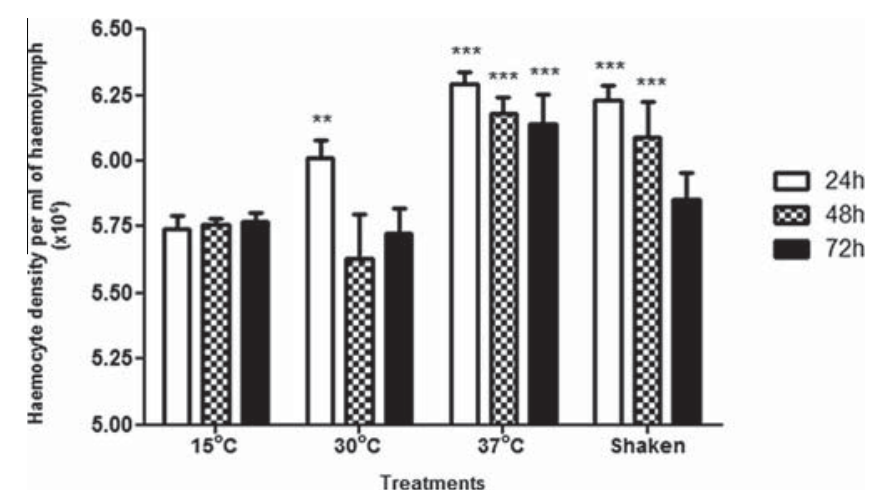

Fig. 2. Haemocyte density of larvae thermally $\left(15^{\circ} \mathrm{C}, 30^{\circ} \mathrm{C}\right.$ and $\left.37^{\circ} \mathrm{C}\right)$ or physically stressed (shaken) at 24,48 or $72 \mathrm{~h}$.

compared to larvae that received the same treatments but were infected $72 \mathrm{~h}$ after initiation of the stress event (fig. 1).

\subsection{Effect of physical and thermal stress on haemocyte density}

Exposing larvae to physical or thermal stresses lead to an increase in the density of circulating haemocytes in the haemolymph $24 \mathrm{~h}$ later (Fig. 2). In particular larvae incubated at $37^{\circ} \mathrm{C}$ for $24 \mathrm{~h}$ showed $6.23 \pm 0.04 \times 10^{7}$ haemocytes per $\mathrm{ml}$ haemolymph compared to $5.97 \pm 0.04 \times 10^{7}$ per $\mathrm{ml}$ in larvae incubated at $15^{\circ} \mathrm{C}(p=0.001)$. Those larvae that were physically stressed showed a similar increase in haemocyte density at $24 \mathrm{~h}$ i.e. $\left(6.23 \pm 0.05 \times 10^{7} / \mathrm{ml}\right)$. Interestingly the haemocyte density in larvae pre-incubated at $37^{\circ} \mathrm{C}$ or physically stressed declined at 48 and $72 \mathrm{~h}$ possibly suggesting a return to pre-stress levels. Larvae incubated at $15^{\circ} \mathrm{C}$ showed no significant alteration in haemocyte density over the $72 \mathrm{~h}$.

\subsection{Analysis of changes in protein expression in stressed larvae}

Larvae were thermally or physically stressed as described and incubated for 24,48 or $72 \mathrm{~h}$ at 15,30 or $37^{\circ} \mathrm{C}$ as appropriate. Protein was extracted from larvae and resolved by 1-D SDS-PAGE as described. Analysis of the alterations in the intensity of apolipophorin (Accession No: AAT76806, 22\% coverage, score 1241), prophenoloxidase (PPO) (Accession No: AAK64363, 5\% coverage, score 91) and arylophorin (Accession No: AAA19801, 32\% coverage, score 1113), revealed the increased intensity of all three proteins in sera from larvae incubated at $37^{\circ} \mathrm{C}$ or physically stressed at $24 \mathrm{~h}$ (Fig. $3 \mathrm{~A}-\mathrm{C})$. However the relative intensity of these three proteins was reduced at 48 and $72 \mathrm{~h}$.

In order to examine whether there was a prolonged change in the expression of a range of proteins following a thermal stress haemolymph was extracted from larvae incubated at $37^{\circ} \mathrm{C}$ for 24,48 or $72 \mathrm{~h}$ and resolved by 2D SDS-PAGE (Fig. 4). A number of proteins with immune functions were shown to be increased in intensity at $24 \mathrm{~h}$ but declined thereafter (Table 1 ). The $26 \mathrm{kDa}$ (spot 4) and $32 \mathrm{kDa}$ ferritin (spot 5) proteins are important in maintaining the homeostasis of iron in the haemocoel and have important roles in the immune response (Levy et al., 2004). Both proteins show a 1.34-1.4-fold increase in intensity at $24 \mathrm{~h}$ but this declined at 48 and $72 \mathrm{~h}$. Transferrin (spot 1) showed a 2.27-fold increase in expression at $24 \mathrm{~h}$ compared to the control, however the intensity declined to 1.62 and 1.25 -fold at 48 and $72 \mathrm{~h}$, respectively. Apolipophorin III (spot 3) has several functions including lipid transport and a function in the innate immune response (Gupta et al., 2010) and showed a 1.82-fold increase in intensity at $24 \mathrm{~h}$ but this declined to 0.95 and 0.7 -fold at $48 \mathrm{~h}$ and $72 \mathrm{~h}$ 
A
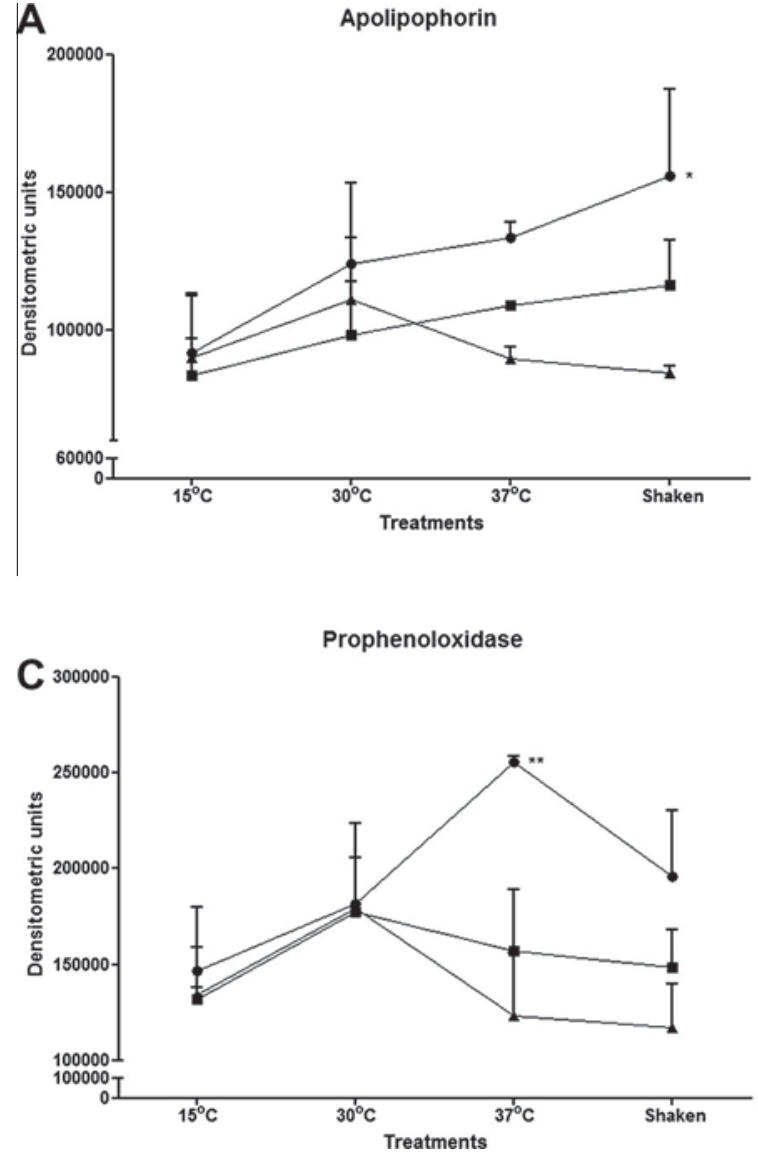

B

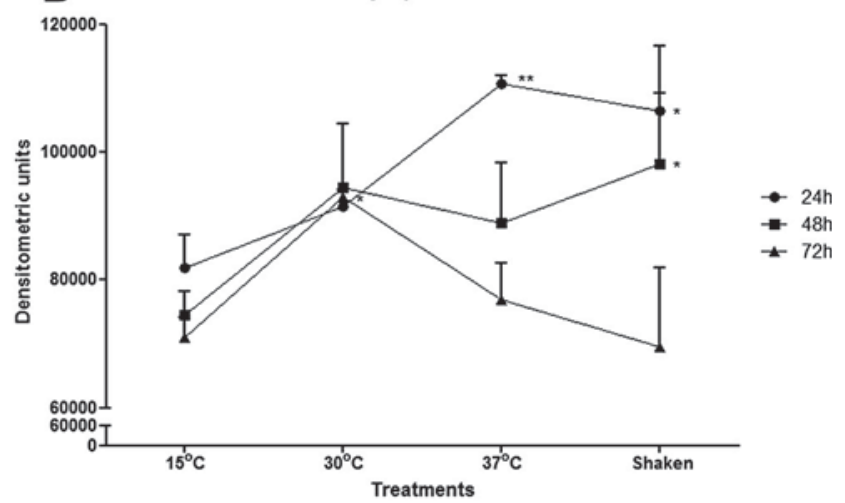

D

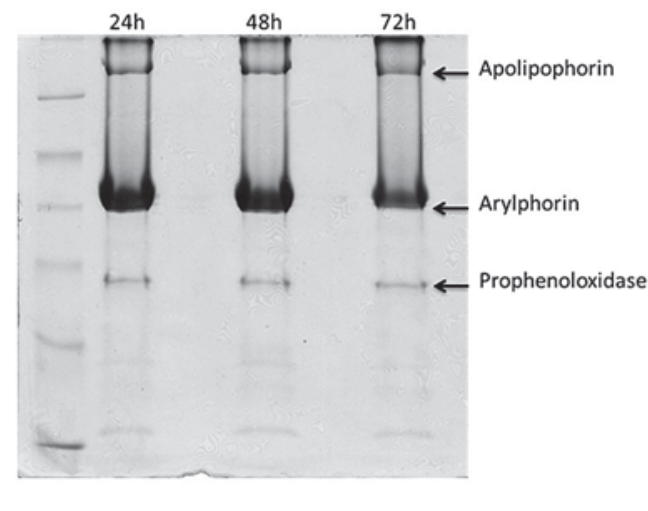

Fig. 3. Relative expression of apolipophorin (A), arylophorin (B) and prophenoloxidase (C) in sera from G. mellonella larvae physically or thermally stressed at 24,48 or $72 \mathrm{~h}$. Representative gel of separated haemolymph proteins on $12.5 \%$ SDS-PAGE with proteins of interest indicated (D).

respectively. Arylophorin (spot 9) showed an increase in expression of 1.9 -fold at $24 \mathrm{~h}$ but the intensity reduced to 0.53 and 0.59 -fold at 48 and $72 \mathrm{~h}$, respectively. Arylophorin is a storage protein for amino acids and aids in the immune defense of insects (Beresford et al., 1997). Serpin 1 (spot 6) demonstrated a 1.46-fold increase in expression at $24 \mathrm{~h}$ but its relative expression decreased thereafter. The expression of juvenile growth hormone precursor (spot 8) was maintained at a relatively constant level across the time points and may be considered as a loading control (Banville et al., 2012).

\section{Discussion}

The results presented here indicate that mild physical and/or thermal stress can increase the resistance of $G$. mellonella larvae to infection by A. fumigatus if larvae are inoculated $24 \mathrm{~h}$ after the initiation of the stress event. Larvae thermally or physically stressed for $24 \mathrm{~h}$ prior to infection demonstrated an increase in haemocyte density and in the expression of a number of antimicrobial proteins. In contrast, those larvae inoculated $72 \mathrm{~h}$ after the initiation of the stress events demonstrated no enhanced resistance to infection by this pathogen.

The abundance of prophenoloxidase, arylophorin and apolipophorin was increased at $24 \mathrm{~h}$ in those larvae that had been thermally or physically stressed but the expression of these proteins declined in larvae incubated for 48 and $72 \mathrm{~h}$. A short term increase in abundance of either prophenoloxidase or phenoloxidase (PO) may be due to two possible scenarios. PPO is the inactive storage form of the enzyme which may increase for an immune investment, whereas PO reflects the active enzyme used in active components of the immune response (Bocher et al., 2007). An increase in
PPO could occur as part of priming for an immune response to a potential infection within the larvae whereas the activated PO would be required for dealing with an active infection within the larvae (Berisha et al., 2013).

The haemocyte density of larvae incubated at $37{ }^{\circ} \mathrm{C}$ or physically stressed reached the highest value at $24 \mathrm{~h}$ but declined at 48 and $72 \mathrm{~h}$.

Immune priming is well characterized in insects and serves to protect the insect from a potentially lethal infection by raising immune defences following exposure to a sub-lethal infection. We previously established that non-lethal physical and thermal stress can lead to increased resistance of $G$. mellonella to infection with the yeast Candida albicans (Mowlds et al., 2008; Mowlds and Kavanagh 2008). In this work we have extended these observations and demonstrated that the priming effect in G. mellonella larvae is a short term event that declines after $24 \mathrm{~h}$.

Immune priming in insects has the advantage of giving protection from a subsequent potentially lethal infection but is costly to maintain and can result in death if compensatory feeding is unavailable (Moret and Schmid-Hempel, 2000). Immune priming can also be affected by the social interaction and behaviour of challenged bees (Richard et al., 2008). Immune priming in Formica selysi workers following challenge with Beauveria bassiana is short term (Reber and Chapuisat, 2012) raising the possibility that colony living precludes the necessity of having a prolonged immune priming effect as other compensatory mechanisms may be operating in the colony. For example, in honey bee colonies an elevated nest temperature is generated as a colony-level response to prevent chalk brood (Starks et al., 2000). Social immunity in insects has been suggested in a number of colony based communities and it has been demonstrated that ants which are infected within 


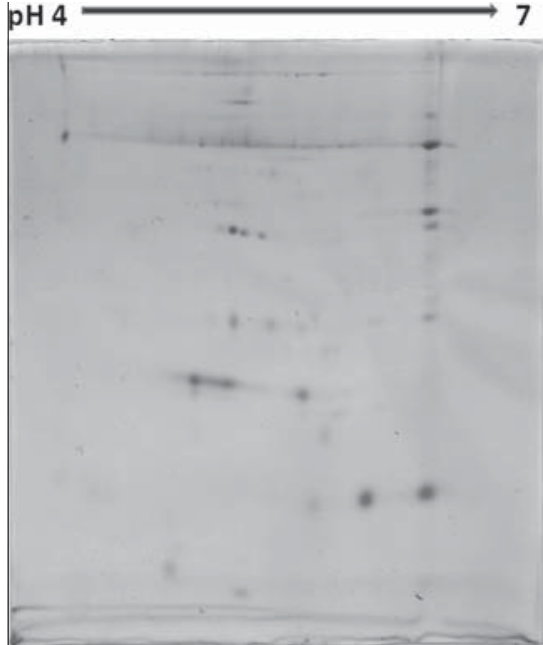

A

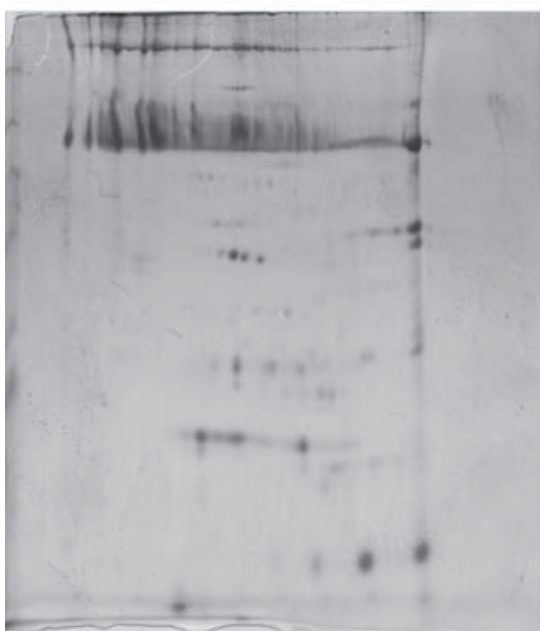

C
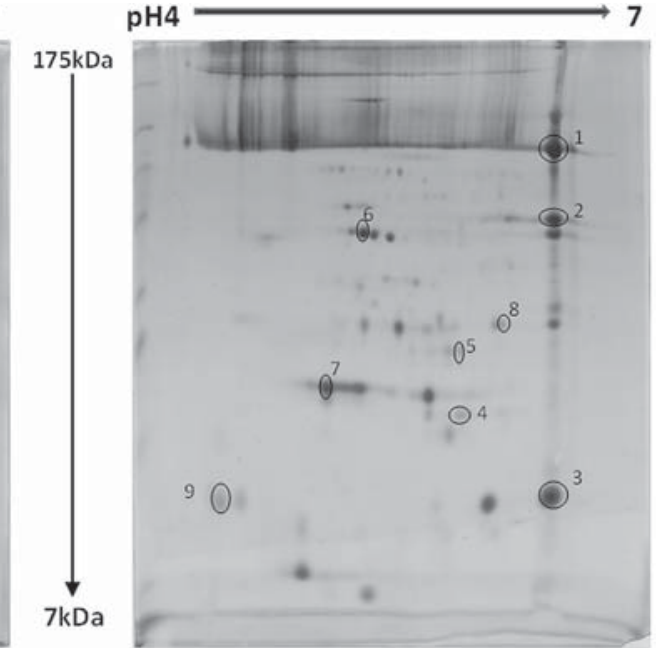

B

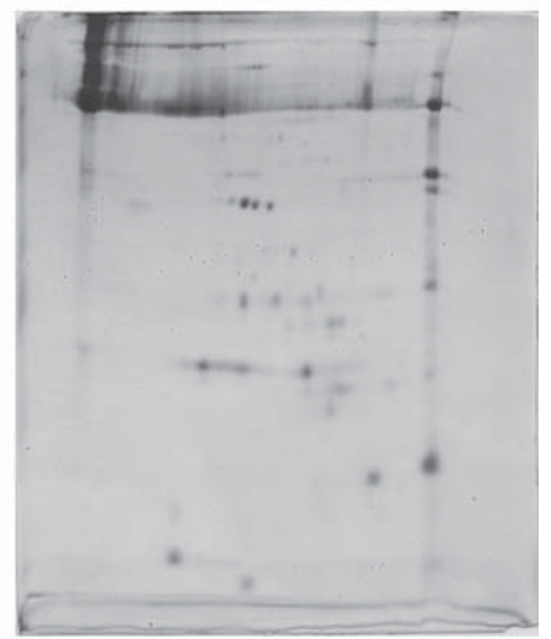

D

Fig. 4. 2D SDS-PAGE of separated haemolymph proteins from G. mellonella larvae incubated at $37{ }^{\circ} \mathrm{C}$ for $0 \mathrm{~h}(\mathrm{~A}), 24 \mathrm{~h}(\mathrm{~B}), 48 \mathrm{~h}(\mathrm{C})$ or $72 \mathrm{~h}$ (D). Proteins of interest (1-9) were excised and identified by LC-Mass spectrometry.

Table 1

Relative expression of proteins isolated from haemolymph of G. mellonella larvae incubated at $37{ }^{\circ} \mathrm{C}$ for 24,48 or $72 \mathrm{~h}$.

\begin{tabular}{|c|c|c|c|c|c|c|c|c|c|}
\hline & \multirow[t]{2}{*}{ Protein identity } & \multirow[t]{2}{*}{ Organism } & \multirow[t]{2}{*}{ Score } & \multirow[t]{2}{*}{ Seq. coverage (\%) } & \multirow[t]{2}{*}{ Accession number } & \multirow[t]{2}{*}{$0 \mathrm{~h}$ (control) } & \multicolumn{3}{|c|}{ Relative expression } \\
\hline & & & & & & & $24 \mathrm{~h}$ & $48 \mathrm{~h}$ & $72 \mathrm{~h}$ \\
\hline 1 & Transferrin precursor & Galleria mellonella & 340 & 8 & AAQ63970 & 1 & $1.93^{*}$ & 1.33 & 1.17 \\
\hline 2 & Imaginal disc growth factor-like protein & Mamestra brassicae & 158 & 13 & ABC79625 & 1 & 1.77 & 1.18 & 1.18 \\
\hline 3 & Apolipophorin-3 & Galleria mellonella & 604 & 66 & P80703 & 1 & 1.72 & 1.07 & 1.04 \\
\hline 4 & $26 \mathrm{kDa}$ ferritin subunit & Galleria mellonella & 504 & 44 & AAG41120 & 1 & 1.46 & 1.23 & 1.13 \\
\hline 5 & $32 \mathrm{kDa}$ ferritin subunit & Galleria mellonella & 469 & 35 & AAL47694 & 1 & $2.03^{* * *}$ & 1.13 & 0.97 \\
\hline 6 & Serpin 1 & Danaus plexippus & 86 & 6 & EHJ75277 & 1 & 1.59 & 1.13 & 1.34 \\
\hline 7 & 27 kDA glycoprotein precursor & Bombyx mori & 93 & 7 & Q8T113 & 1 & $1.99^{*}$ & 1.36 & 0.99 \\
\hline 8 & Juvenile hormone binding protein precursor & Galleria mellonella & 262 & 24 & AAS94224 & 1 & 1.21 & 1.11 & 0.99 \\
\hline 9 & Arylphorin & Galleria mellonella & 168 & 5 & AAA74229 & 1 & $1.91^{*}$ & 0.90 & 0.95 \\
\hline
\end{tabular}

${ }^{*} p<0.05$.

$p<0.001$.

a colony can regurgitate droplets which were capable of transferring immune factors to other uninfected ants (Hamilton et al., 2011). Traniello et al. (2002) demonstrated that naïve termites reared alongside termites previously exposed to Metarhizium anisopliae can improve the subsequent resistance of the naïve termites to the fungal pathogen. A potential role for 'behavioural fever', where insects alter their temperature through thermoregulatory behaviour, leading to an increased ability to withstand infection has been suggested (Watson et al., 1993; Blanford et al., 1998; Elliot et al., 2002).

The enhanced immune protection afforded by the priming events described here in G. mellonella larvae reached a peak $24 \mathrm{~h}$ 
after the initiation of the stress event and then declined. The relatively short duration of the immune priming effect in Galleria may be due to the fact that in its normal habitat G. mellonella live in bee colonies where the high temperature may offer some degree of protection against pathogens thus not necessitating a long term, heightened immune response that may be metabolically costly to maintain. In contrast to other insects, ants do not show immune priming when challenged with $B$. bassiana and it has been suggested that behavioral or group level chemical defences may limit infection and thus remove the necessity for an immune priming response (Reber and Chapuisat, 2012). The observation of a short term $(24 \mathrm{~h})$ immune priming effect in G. mellonella larvae is of interest in that it may have evolved as a response to life within the colony of another insect. This raises the possibility of the immune response of one insect (i.e. G. mellonella) being modulated by living in the colony of another (i.e. Apis mellifera).

Insects, and larvae of $G$. mellonella in particular, are now widely used in industry and academia as in vivo models (Kavanagh and Fallon, 2010) and give results comparable to those that can be obtained using mammals (Jander et al., 2000). However no standardized incubation conditions have been accepted (Cook and McArthur, 2013). The results presented here demonstrate that larvae are sensitive to alteration in temperature and mild physical stress, factors that may affect the reliability of results generated using these larvae.

\section{Conflict of interest}

The authors have no conflicts of interest to declare.

\section{Acknowledgement}

N. Browne is the recipient of a Hume Postgraduate Scholarship from NUI Maynooth, C. Surlis is the recipient of an Irish Research Council Scholarship.

\section{References}

Banville, N., Browne, N., Kavanagh, K., 2012. Effect of nutrient deprivation on the susceptibility of Galleria mellonella larvae to infection. Virulence 6, 1-7.

Beresford, P.J., Basinski-Gray, J.M., Chiu, J.K., Chadwick, J.S., Aston, W.P., 1997. Characterization of hemolytic and cytotoxic Gallysins: a relationship with arylphorins. Dev. Comp. Immunol. 21, 253-266.

Bergin, D., Murphy, L., Keenan, J., Clynes, M., Kavanagh, K., 2006. Pre-exposure to yeast protects larvae of Galleria mellonella from a subsequent lethal infection by Candida albicans and is mediated by the increased expression of antimicrobial peptides. Microbes Infect. 8, 2105-2112.

Berisha, A., Mukherjee, K., Vilcinskas, A., Spengler, B., Römpp, A., 2013. Highresolution mass spectrometry driven discovery of peptidic danger signals in insect immunity. PLoS One 11, e80406. http://dx.doi.org/10.1371/journal. pone.0080406.

Blanford, S., Thoma, M.B., Langewald, J., 1998. Behavioural fever in the Senegalese grasshopper, Oedaleus senegalensis, and its implications for biological contro using pathogens. Ecol. Entomol. 23, 9-14.

Bocher, A., Tirard, C., Doums, C., 2007. Phenotypic plasticity of immune defence linked with foraging activity in the ant Cataglyphis velox. J. Evol. Biol. 20, 2228 2234.

Cook, S., McArthur, J.D., 2013. Developing Galleria mellonella as a model host for human pathogens. Virulence 4, 350-353.

Cotter, G., Doyle, S., Kavanagh, K., 2000. Development of an insect model for the in vivo pathogenicity testing of yeasts. FEMS Immunol. Med. Microbiol. 27, 163169.

De Gregorio, E., Spellman, P.T., Rubin, G.M., Lemaitre, B., 2001. Genome-wide analysis of the Drosophila immune response by using oligonucleotide microarrays. Proc. Natl. Acad. Sci. 98, 12590-12595.

Elliot, S.L., Blanford, S., Thomas, M.B., 2002. Host-pathogen interactions in a varying environment: temperature, behavioural fever and fitness. Proc. R. Soc. Lond. B Biol. Sci. 269, 1599-1607.

Gupta, L., Noh, J.Y., Jo, Y.H., Oh, S.H., Kumar, S., Noh, M.Y., Lee, Y.S., Cha, S.J., Seo, S.J. Kim, I., Han, Y.S., Barillas-Mury, C., 2010. Apolipophorin-III mediates antiplasmodial epithelial responses in Anopheles gambiae (G3) mosquitoes. PLoS One 5, e15410.
Hamilton, C., Lejeune, B.T., Rosengaus, R.B., 2011. Trophallaxis and prophylaxis: social immunity in the carpenter ant Camponotus pennsylvanicus. Biol. Lett. 7, 89-92.

Heard, N.A., Holmes, C.C., Stephens, D.A., Hand, D.J., Dimopoulos, G., 2005. Bayesian co-clustering of Anopheles gene expression time series: study of immune defense response to multiple experimental challenges. Proc. Natl. Acad. Sci. USA 47, 16939-16944.

Hornsey, M., Wareham, D.W., 2011. In vivo efficacy of glyco-peptide-colistin combination therapies in a Galleria mellonella model of Acinetobacter baumannii infection. Antimicrob. Agents Chemother. 55, 3534-3537.

Irving, P., Troxler, L., Heuer, T.S., Belvin, M., Kopczynski, C., Reichhart, J.M., Hoffmann, J.A., Hetru, C., 2001. A genome-wide analysis of immune responses in Drosophila. Proc. Natl. Acad. Sci. USA 98, 15119-15124.

Jander, G., Rahme, L., Ausbel, F., 2000. Positive correlation between virulence of Pseudomonas aeruginosa mutants in mice and insects. J. Bacteriol. 182, 3843 3845.

Kavanagh, K., Fallon, J., 2010. Galleria mellonella larvae as models for studying fungal virulence. Fungal Biol. Rev. 24, 79-83.

Kavanagh, K., Reeves, E.P., 2004. Exploiting the potential of insects for in vivo pathogenicity testing of microbial pathogens. FEMS Microbiol. Rev. 28, 101112.

Lemaitre, B., Reichhart, J.M., Hoffmann, J.A., 1997. Drosophila host defense: differential induction of antimicrobial peptide genes after infection by various classes of microorganisms. Proc. Natl. Acad. Sci. USA 94 (26), 14614-e14619 (1997).

Levy, F., Bulet, P., Ehret-Sabatier, L., 2004. Proteomic analysis of the systemic immune response of Drosophila. Mol. Cell Proteomics 3, 156-166.

Little, T.J., Kraaijeveld, A.R., 2004. Ecological and evolutionary implications of immunological priming in invertebrates. Trends Ecol. Evol. 19, 58-60.

Moret, Y., Schmid-Hempel, P., 2000. Survival for immunity: the price of immune system activation for bumblebee workers. Science 290, 1166-1168.

Mowlds, P., Kavanagh, K., 2008. Effect of pre-incubation temperature on susceptibility of Galleria mellonella to infection by Candida albicans. Mycopathologia 165, 5-12.

Mowlds, P., Barron, A., Kavanagh, K., 2008. Physical stress primes the immune response of Galleria mellonella larvae to infection by Candida albicans. Microbes Infect. 10, 628-634.

Mowlds, P., Coates, C., Renwick, J., Kavanagh, K., 2010. Dose-dependent cellular and humoral responses in Galleria mellonella larvae following $\beta$-glucan inoculation. Microbes Infect. 12, 146-153.

Mukherjee, K., Hain, T., Fischer, R., Chakraborty, T., Vilcinskas, A., 2013. Brain infection and activation of neuronal repair mechanisms by the human pathogen Listeria monocytogenes in the lepidopteran model host Galleria mellonella. Virulence 4, 324-332.

Pech, L.L., Strand, M.R., 1996. Granular cells are required for encapsulation of foreign targets by insect haemocytes. J. Cell Sci. 109, 2053-2060.

Pham, L.N., Dionne, M.S., Shirasu-Hiza, M., Schneider, D.S., 2007. A specific primed immune response in Drosophila is dependent on phagocytes. PLoS Pathog. 3 e26.

Pletcher, S.D., Libert, S., Skorupa, D., 2005. Flies and their golden apples: the effect of dietary restriction on Drosophila aging and age-dependent gene expression. Ageing Res. Rev. 2005 (4), 451-480.

Ratcliffe, N.A., 1985. Invertebrate immunity-a primer for the non-specialist. Immunol. Lett. 10, 253-270.

Ratcliffe, N.A., 1993. Cellular defense responses of insects: unresolved problems. In: Beckage, N.E., Thompson, S.N., Federici, B.A. (Eds.), Parasites and Pathogens of Insects, vol. 1: Parasites. Academic Press, London, pp. 267-304.

Reber, A., Chapuisat, M., 2012. No evidence for immune priming in ants exposed to a fungal pathogen. PLoS One 7 (4), e35372.

Richard, F.J., Aubert, A., Grozinger, C.M., 2008. Modulation of social interactions by immune stimulation in honey bee, Apis mellifera, workers. BMC Biol. 6, 50. http://dx.doi.org/10.1186/1741-7007/6/50.

Rowan, R., Moran, C., McCann, M., Kavanagh, K., 2009. Use of Galleria mellonella larvae to evaluate the in vivo anti-fungal activity of [Ag2(mal)(phen)3]. Biometals 22, 461-467.

Sadd, B.M., Schmid-Hempel, P., 2006. Insect immunity shows specificity in protection upon secondary pathogen exposure. Curr. Biol. 16, 1206-1210.

Schulenburg, H., Kurz, C.L., Ewbank, J.J., 2004. Evolution of the innate immune system: the worm perspective. Immunol. Rev. 198, 36-58.

Shevchenko, A., Tomas, H., Havlis, J., Olsen, J.V., Mann, M., 2006. In-gel digestion for mass spectrometric characterization of proteins and proteomes. Nat. Protoc. 1 2856-2860.

Starks, P.T., Blackie, C.A. Seeley, T.D., 2000. Fever in honeybee colonies. Naturwissenschaften 87, 229-231.

Traniello, J.F.A., Rosengaus, R.B., Savoie, K., 2002. The development of immunity in a social insect: evidence for the group facilitation of disease resistance. Proc. Natl. Acad. Sci. USA 99, 6838-6842.

Watson, D.W., Mullens, B.A., Petersen, J.J., 1993. Behavioral fever response of Musca domestica (Diptera, Muscidae) to infection by Entomophthora muscae (Zygomycetes, Entomophthorales). J. Invertebr. Pathol. 61, 10-16.

Wojda, I., Jakubowicz, T., 2007. Humoral immune response upon mild heat-shock conditions in Galleria mellonella larvae. J. Insect Physiol. 53, 1134-1144.

Zhang, S.M., Loker, E.S., 2004. Representation of an immune responsive gene family encoding fibrinogen-related proteins in the freshwater mollusc Biomphalaric glabrata, an intermediate host for Schistosoma mansoni. Gene 341, 255-266. 